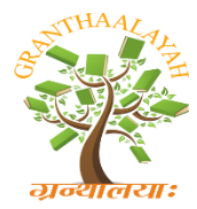

\author{
INTERNATIONAL JOURNAL OF RESEARCH \\ GRANTHAALAYAH \\ A knowledge Repository
}

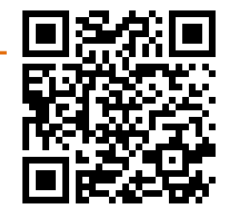

Science

\title{
MEDICATION ADHERENCE AND QUALITY OF LIFE AMONG EPILEPSY PATIENTS: A CROSS SECTIONAL STUDY
}

\author{
Pande Ayu Naya Kasih Permatananda ${ }^{* 1}$, Putu Indah Budi Apsari ${ }^{2}$, Saktivi Harkitasari ${ }^{3}$ \\ ${ }^{* 1}$ Department of Pharmacology and Pharmacy, Faculty of Medicine and Health Sciences, \\ Universitas Warmadewa, Indonesia \\ 2 Department of Microbiology and Parasitology, Faculty of Medicine and Health Sciences, \\ Universitas Warmadewa, Indonesia \\ ${ }^{3}$ Department of Neurology, Faculty of Medicine and Health Sciences, Universitas Warmadewa, \\ Indonesia
}

\begin{abstract}
Background: Among the cause of the treatment failure in epilepsy, low adherence to prescribed medication is the principal cause of unsuccessful drug treatment. The aim of this study was to assess the level of adherence and the relations with quality of life among epilepsy patients in Denpasar.

Method: Our research based on cross sectional design and conducted in neurology department of tertiary referral hospital in Denpasar. We used Morisky Medication Adherence Scale (MMAS) to measure level of adherence and World Health Organization (WHOQOL-BREF) questionnaire to assess quality of life (QOL) score.

Results: On this research, we found 83 epilepsy patients who fulfilled eligibility criteria, there are 43 patients categorized as non-adherent and 39 patients belong to adherent. Based on the cross tabulation between characteristic of participants and adherence, we found that age and duration of therapy influence the adherence level of epilepsy patient ( $\mathrm{p}$ value < 0.05 ). Epilepsy patients who adherent to the treatment have higher score of QOL than epilepsy patients who not adherent, especially on physical domain of QOL, the difference was statistically significant ( $\mathrm{p}$ value < 0.05 ). Conclusion: Improving adherence is so important to improve the quality of life of epilepsy patients.
\end{abstract}

Keywords: Medication Adherence; Quality of Life; Epilepsy.

Cite This Article: Pande Ayu Naya Kasih Permatananda, Putu Indah Budi Apsari, and Saktivi Harkitasari. (2019). "MEDICATION ADHERENCE AND QUALITY OF LIFE AMONG EPILEPSY PATIENTS: A CROSS SECTIONAL STUDY.” International Journal of Research Granthaalayah, 7(3), 1-10. https://doi.org/10.29121/granthaalayah.v7.i3.2019.937. 


\section{Introduction}

Epilepsy has been defined as disorder of brain characterized by an enduring predisposition to generate epileptic seizures, and by the neurobiological, cognitive, psychological, and social consequences of this condition. Epilepsy belong to common serious neurological disorders affecting 50 million people worldwide, with no boundary to age, race, social class, nationality, or geographical location [1-2]. Antiepileptic drug (AED) therapy aims to achieve a balance between the prevention of seizure episodes, and the reduction of side effects of AEDs to tolerable levels, to improve the patient's quality of life, provide cost-effective care, and ensure patient satisfaction [3]. Good adherence to treatment and proper health education are fundamental to the successful management of epilepsy.

Among the cause of the treatment failure in epilepsy, low adherence to prescribed medication is the principal cause of unsuccessful drug treatment. Previous literature about epilepsy management stated that increasing the effectiveness of adherence interventions may have a far greater impact on the health of the population than any improvement in specific medical treatment [1]. Medication non adherence described as a voluntary or involuntary behaviour of medication intake which includes failing initially filling or refilling a prescription, discontinuing a medication before the course of therapy is completed, inability to adhere with agreed recommendations from health care provider, taking more or less of a medication than prescribed, and taking a dose at wrong time [2]. Several methods have been proposed for adherence measurement. Determining levels of a drug or its metabolite in body fluids is an objective measure, but AED blood levels may only reflect some medication that was taken in previous day. A number of indirect measures of therapeutic adherence also have been used, such as pill counts, pharmacy records, and some self-report questionnaire $[1,4]$.

The magnitude of antiepileptic drug non adherence is ranged from $26 \%$ in USA to $67 \%$ in Nigeria $[5,6]$. A primary care based study in UK showed that the prevalence of antiepileptic drug non adherence was $36.4 \%$ and those who were on multidrug treatment were tend to be noncompliant with their treatment [7]. Antiepileptic drugs (AED) are effective in the treatment of epilepsy, but poor adherence to medication is major problem to sustained remission and functional restoration resulted in treatment failure and seizure recurrence. Even though around $70 \%$ of people who had epilepsy supposed to be seizure free with optimum AED treatment, many people with epilepsy did not take their antiepileptic drugs appropriately and the mortality rate in non-adherent patients was more than threefold higher than that of adherent ones [8-10].

Quality of life is one of the important goals of the management of epilepsy despite of seizure remission [11]. According to World Health Organization (WHO), quality of life is defined as individuals' perceptions of their position in life in the context of the culture and value systems in which they live and in relation to their goals, expectations, standards and concerns [12]. Previous studies related to the quality of life of epilepsy patients in Bali found that all the subjects were found to have good adherence to the treatment of epilepsy. Compliance was assessed by calculating the value of Medication Posses Ratio (MPR) by calculating the distance of the visit to see the refill ratio with the time of visit, the MPR value of $\geq 80$ subjects was called obedient. Although the evaluation with the MPR is valid, some respondents claimed that they often did not consume the drug because they forgot or felt healthy [13]. The purpose of this study was to examine the compliance of epilepsy patients in carrying out their treatment as well as the factors 
involved in it. This study also intends to measure the quality of life of epilepsy patients by using a WHO questionnaire that assesses the quality of life of epilepsy patients through four parameters, namely physical, psychological, social, and environmental, as well as looking at the relationship between adherence level and patients' quality of life.

\section{Materials and Methods}

This research was based on cross sectional study design that was conducted on Neurology policlinic at Regional Hospital Wangaya, Denpasar, Indonesia. Regional Hospital Wangaya is belong to a tertiary referral hospital that is located in Denpasar, capital city of Bali. Adults individual above 17 years of age who were diagnosed for epilepsy and have been on AED treatments for at least three months were included in the study and individuals who were unable to communicate due to serious neurological deficit and other serious illness were excluded. The study was approved by the Institution Ethics Committee of Universitas Gadjah Mada prior to commencement. Written valid informed consent was obtained from all participants before administering study instrument.

Data collection was done by the principal investigator in face to face interviews to the participant. Study instrument consist of three parts. The first parts comprised baseline characteristic of participants, include demographic, clinic, and therapy. The second parts gathered information about Medication Adherence profile with the aid of Morisky Medication Adherence Scale-8 (MMAS-8). It is an 8-item questionnaire with seven yes/no questions and one question answered on a 5-point Likert Scale. According to scoring system for the MMAS, 8 means high adherence, 6-8 means medium adherence, and below 6 means low adherence. MMAS-8 questionnaire has been translated and used for various disease in Indonesia. The third parts were WHO QOL-BREF questionnaire that consisted of validated and reliable 26-item scale measuring the following broad domains of quality of life: physical health, psychological health, social relationship, and environment; with each question rated on a 5-point Likert-type scale. The four domain scores are scaled out of 100 each, in a positive direction; implying that higher score reflect a higher quality of life.

All data obtained were tabulated and presented descriptively. We used chi square tests to see association between categorical variables and medication adherence and statistical test using Independent $\mathrm{T}$ test was performed to see the difference of quality of life score between each level of adherence.

\section{Results}

From 96 epileptic patients, only 83 patients fulfilled eligibility criteria. Baseline characteristic included demographic, clinical, and therapy characteristic of study population are shown in table 1 . 
Table 1: Baseline Characteristic

\begin{tabular}{|c|c|c|}
\hline \multicolumn{2}{|c|}{ Characteristic } & \multirow{2}{*}{ 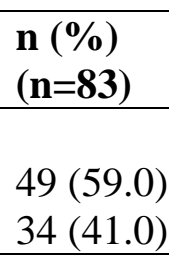 } \\
\hline 1 & $\begin{array}{l}\text { Age } \\
-<40 \text { y.o } \\
-\geq 40 \text { y.o }\end{array}$ & \\
\hline 2 & $\begin{array}{l}\text { Gender } \\
\text { - Male } \\
\text { - Female }\end{array}$ & $\begin{array}{l}45(54.2) \\
38(45.8) \\
\end{array}$ \\
\hline 3 & $\begin{array}{l}\text { Education } \\
\text { - Low Education } \\
\text { - High education }\end{array}$ & $\begin{array}{l}30(36.1) \\
54(65.1)\end{array}$ \\
\hline 4 & $\begin{array}{l}\text { Occupation } \\
\text { - Unemployment } \\
\text { - Working }\end{array}$ & $\begin{array}{l}44(53.0) \\
39(47.0)\end{array}$ \\
\hline 5 & $\begin{array}{l}\text { Type of epilepsy } \\
\text { - Focal } \\
\text { - Generalized }\end{array}$ & $\begin{array}{l}13(15.7) \\
70(84.3)\end{array}$ \\
\hline 6 & $\begin{array}{l}\text { Seizure Frequency before treatment } \\
-<4 x \\
-\geq 4 x\end{array}$ & $\begin{array}{l}70(84.3) \\
13(15.7) \\
\end{array}$ \\
\hline 7 & $\begin{array}{l}\text { Family History of Epilepsy } \\
\text { - Yes } \\
\text { - No }\end{array}$ & $\begin{array}{l}8(9.6) \\
75(90.4) \\
\end{array}$ \\
\hline 8 & $\begin{array}{l}\text { Seizure Remission in last } 6 \text { months } \\
\text { - Yes } \\
\text { - No }\end{array}$ & $\begin{array}{l}42(50.6) \\
41(49.4) \\
\end{array}$ \\
\hline 9 & $\begin{array}{l}\text { Type of Therapy } \\
\text {-Monotherapy } \\
\text {-Polytherapy }\end{array}$ & $\begin{array}{l}37(44.6) \\
46(53.4) \\
\end{array}$ \\
\hline 10 & $\begin{array}{l}\text { Duration of Therapy } \\
-<10 \text { years } \\
->10 \text { years }\end{array}$ & $\begin{array}{l}51(61.4) \\
32(38.6) \\
\end{array}$ \\
\hline 11 & $\begin{array}{l}\text { Adverse Event } \\
\text { - Yes } \\
\text { - No }\end{array}$ & $\begin{array}{l}75(90.3) \\
8(9.6)\end{array}$ \\
\hline
\end{tabular}

Adherence level based on MMAS-8 result divided into low, medium, and high. But, we only got one patients who had high level of adherence, so we divided the adherence level just into two categories: not-adherent and adherent. Subjects who had MMAS score below 6 categorized as not adherent and subjects who had MMAS score more than 6, we called them as adherent. According to MMAS-8 score, $43(51.8 \%)$ of the subjects were considered to be not-adherent and the remaining, $39(48.2 \%)$ of the subjects were adherent to antiepileptic medication. From the cross tabulation of adherence and subject characteristic, we found that age and duration of therapy influence adherence level of epileptic patients $(\mathrm{p}<0.05)$, as shown in table 2. Epileptic patients 
below 40 years old had higher level of adherence than older epileptic patients. Epileptic patients with longer duration of treatment more prone to be not adherent than shorter treatment.

Table 2: Adherence Level in Epilepsy Patients

\begin{tabular}{|c|c|c|c|c|}
\hline \multirow{2}{*}{\multicolumn{2}{|c|}{ Characteristic }} & \multirow{2}{*}{\multicolumn{2}{|c|}{ Adherence }} & \multirow[t]{2}{*}{ p Value } \\
\hline & & & & \\
\hline 1 & $\begin{array}{l}\text { Age } \\
-<40 \text { y.o } \\
-\geq 40 \text { y.o }\end{array}$ & \begin{tabular}{|l|}
$\begin{array}{l}\text { Not Adherent }(\%) \\
(\mathbf{n}=43)\end{array}$ \\
$18(36.7)$ \\
$26(76.5)$ \\
\end{tabular} & $\begin{array}{l}\begin{array}{l}\text { Adherent (\%) } \\
(\mathbf{n}=39)\end{array} \\
31(63.3) \\
8(23.5) \\
\end{array}$ & $0.001 *$ \\
\hline 2 & $\begin{array}{l}\text { Gender } \\
\text { - Male } \\
\text { - Female } \\
\end{array}$ & $\begin{array}{l}21(46.7) \\
23(50.5) \\
\end{array}$ & $\begin{array}{l}24(53.3) \\
15(39.5) \\
\end{array}$ & 0.208 \\
\hline 3 & $\begin{array}{l}\text { Education } \\
\text { - Low Education } \\
\text { - High education } \\
\end{array}$ & $\begin{array}{l}16(55.2) \\
28(51.9)\end{array}$ & $\begin{array}{l}13(44.8) \\
26(48.1)\end{array}$ & 0.773 \\
\hline 4 & $\begin{array}{l}\text { Occupation } \\
\text { - Unemployment } \\
\text { - Working }\end{array}$ & $\begin{array}{l}21(52.5) \\
23(53.5)\end{array}$ & $\begin{array}{l}19(47.5) \\
20(46.5)\end{array}$ & 0.928 \\
\hline 5 & $\begin{array}{l}\text { Type of epilepsy } \\
\text { - Focal } \\
\text { - Generalized }\end{array}$ & $\begin{array}{l}5(46.2) \\
38(54.3)\end{array}$ & $\begin{array}{l}7(53.8) \\
32(47.5)\end{array}$ & 0.590 \\
\hline 6 & $\begin{array}{l}\text { Seizure Frequency before treatment } \\
-<4 x \\
-\geq 4 x\end{array}$ & $\begin{array}{l}38(54.3) \\
6(46.2)\end{array}$ & $\begin{array}{l}32(45.7) \\
7(53.8)\end{array}$ & 0.590 \\
\hline 7 & $\begin{array}{l}\text { Family History of Epilepsy } \\
- \text { Yes } \\
\text { - No }\end{array}$ & $\begin{array}{l}5(61.5) \\
39(52.0)\end{array}$ & $\begin{array}{l}3(37.5) \\
36(48.0)\end{array}$ & 0.572 \\
\hline 8 & $\begin{array}{l}\text { Seizure Remission in last } 6 \text { months } \\
\text { - Yes } \\
\text { - No }\end{array}$ & $\begin{array}{l}26(63.4) \\
18(42.9) \\
\end{array}$ & $\begin{array}{l}15(36.6) \\
24(57.1)\end{array}$ & 0.061 \\
\hline 9 & $\begin{array}{l}\text { Type of Therapy } \\
\text {-Monotherapy } \\
\text {-Polytherapy }\end{array}$ & $\begin{array}{l}17(45.9) \\
27(58.7) \\
\end{array}$ & $\begin{array}{l}20(54.1) \\
19(41.3) \\
\end{array}$ & 0.247 \\
\hline 10 & $\begin{array}{l}\text { Duration of Therapy } \\
-<10 \text { years } \\
->10 \text { years }\end{array}$ & $\begin{array}{l}22(43.1) \\
22(68.8) \\
\end{array}$ & $\begin{array}{l}29(56.9) \\
10(31.3) \\
\end{array}$ & $0.023^{*}$ \\
\hline 11 & $\begin{array}{l}\text { Adverse Event } \\
\text { - Yes } \\
\text { - No }\end{array}$ & $\begin{array}{l}42(56.0) \\
2(25.0) \\
\end{array}$ & $\begin{array}{l}33(44.0) \\
6(75.0) \\
\end{array}$ & 0.095 \\
\hline
\end{tabular}

*statistically significant $(\mathrm{p}$ value $<0.05)$

We measured Quality of Life (QOL) to determine outcome of therapy for epilepsy patients. Table 3 shows the mean and standard deviation scores of WHOQOL-BREF domains. The lowest mean 
score was seen in the physical domain $(53.85 \pm 6.8)$ and the highest score was on environment domain $(55.27 \pm 4.14)$ followed by social domain. From table 4 , we can see the QOL scores with respect to the different of adherence level. Epilepsy patients who adhere to the treatment has higher score of QOL than non-adherent epilepsy patients, the difference was statistically significant ( $p$ value <0.05).

Table 3: Quality of Life Measurement Result Using WHO BREF Questionnaire

\begin{tabular}{|l|l|l|}
\hline Domain & Mean \pm SD & Min - Max score \\
\hline Physical & $53.85 \pm 6.8$ & $44.0-63.0$ \\
\hline Psychological & $54.26 \pm 2.7$ & $50.0-56.0$ \\
\hline Social & $54.42 \pm 8.01$ & $50.0-69.0$ \\
\hline Environment & $55.27 \pm 4.14$ & $50.0-63.0$ \\
\hline
\end{tabular}

Table 4: Differences of Quality of Life Score for Each Adherence Level

\begin{tabular}{|c|c|c|c|c|}
\hline \multirow{2}{*}{\multicolumn{2}{|c|}{ Domain of QOL }} & \multicolumn{2}{|c|}{ Adherence Level } & \multirow{3}{*}{\begin{tabular}{|l|} 
p value \\
$0.005 *$ \\
\end{tabular}} \\
\hline & & Adherent & Not Adherent & \\
\hline 1 & Physic & $55.79 \pm 6.42$ & $51.66 \pm 6.63$ & \\
\hline 2 & Psychological & $54.77 \pm 2.44$ & $53.69 \pm 2.95$ & 0.076 \\
\hline 3 & Social & $54.02 \pm 7.73$ & $54.87 \pm 8.40$ & 0.633 \\
\hline 4 & Environment & $55.72 \pm 3.78$ & $54.76 \pm 4.51$ & 0.301 \\
\hline
\end{tabular}

*statistically significant ( $\mathrm{p}$ value $<0.05$ )

\section{Discussion}

Treatment of epilepsy is necessary to alleviate global burden of such chronic illness. Our objectives were to assess the level of medication adherence and their related factors. This study also conducted to measure the quality of live scores and their association with adherence level. Our research is very essential to do since medication non-adherence is the main cause for therapeutic failure in epilepsy [3]. Our findings exactly could be a step toward bridging the vast knowledge gap regarding the medication non-adherence in chronic disease, likes epilepsy.

AEDs non adherence was assessed by an eight-item Morisky Medication Adherence Scale (MMAS). Its sensitivity and specificity were $93 \%$ and 53\%, respectively, and our participants was considered as non-adherent to AEDs if the score of MMAS was less than 6 [2]. In this study we found the prevalence of antiepileptic drug non adherence among epilepsy patients was $51.8 \%$. It was greater than the study done in USA $26 \%$ and the probable explanation might be the differences in study design (retrospective cohort) and socioeconomic differences [14]. But the finding of this study was lower than the studies done in Brazil, Nigeria, and Palestine which were 66.2\%, 67.4\%, and $64 \%$, respectively, and this difference was probably due to the difference in AEDs multidrug treatment. For instance, $71.1 \%$ of people with epilepsy in Brazil, $85 \%$ in Nigeria, and $63.2 \%$ in Palestine were on multiple AEDs treatment while in this current study, only $53.4 \%$ were in polyAED treatment [15-17].

It is widely recognised that there are no gold standard methods for measuring medication adherence [18]. To classifying adherence is highly dependent on the method employed to measure it. Measuring adherence can be divided into direct (blood levels, observation of drug taking) and 
indirect methods (patients reporting through questionnaires and diaries, pill counts, electronic monitoring). All methods have varying advantages and disadvantages over each other [19]. Different methods often produce different results as in our findings that differ from the previous results that are conducted in same population which is $100 \%$ patients showed MPR greater than or equal to $80 \%$ at last one year and defined as being adherent [20]. The use of $80 \%$ as threshold for being adherent is argued in some literatures that this percentage may not be relevant for epilepsy despite having validity in other chronic illness. Additionally, access to medication does not necessarily equate with the actual act of medication taking $[18,21]$. The MMAS tool as we used in this study where questions are phrased to avoid "yes-saying" and each item measuring a specific medication taking behaviour. Some research has compared it favourably over electronic medication monitoring devices $[18,22]$. But, the use of self-report questionnaires increases the risk of blinding bias, either due to fallible memory or effort to appear responsible [18, 21].

Barriers to AED adherence are multifactorial and reflected the complexities and influences on patient decision making about whether or not to take their medication as prescribed. In relation with previous findings, patient related factors more strongly influenced AED adherence [18]. Our study found significant association between age, duration of therapy, and AED adherence. From this study, adherence was more likely to occur in younger patients (below 40 years old). In a research conducted at Ethiopia, prevalence of non-adherence was highest (100\%) among patient more than 60 years old [23]. Other study also stated that elderly patients aged more than 55 years had the highest rates of non-compliance. This may be due to the fact that elderly patients have more difficulty in following instructions due to cognitive impairment or others physical difficulties, such as problem in swallowing tablets, opening drug containers, handling small tablets, distinguishing colours or identifying markings on drugs [24].

The duration of treatment was also a factor that affected non-adherence. We found that duration of epilepsy treatment and adherence were significantly associated. This finding is similar with the study conducted in Pakistan [24] and Ethiopia [23]. The duration of treatment period was also a factor that affected non-compliance. In a study of epilepsy patients, omission of dose was reported to be more frequent with a longer duration of seizure medication use. The long treatment duration might compromise patients' beliefs about medication effectiveness [24]. Previous study showed that as treatment duration increases, the participants became more likely to be non-adherent. Those people with epilepsy who were being on treatment for 6 years and above were 3.47 times more likely to be non-adherent as compared with participants who were on treatment for 3 months to 1 year and being on treatment for 2-5 years who were 2.32 times more likely to be non-adherent as compared with counterparts $[2,25,26]$.

Based on the guidelines for management of epilepsy in Indonesia in line with the International League against Epilepsy (ILAE), the goal of epilepsy management is to get people with epilepsy to live a normal life and achieve optimal quality of life [20,27]. AED non adherent is associated with adverse clinical outcome, patients may be being incorrectly classified as having refractory epilepsy and get wrong addition of dose and drugs. In addition, non-compliance to AEDs has been reported to increase mortality and morbidity as well as decrease quality of life and productivity. Non-compliance was also reported to be associated with reduced mental and emotional wellbeing, included impaired cognition $[18,24]$. The pattern of domain scores in our study showed a higher mean score in environmental domain followed by social domain. The least score was seen on 
physical domain. Similar studies conducted on epileptic subjects using WHO-QOL BREF questionnaire differed from our findings by showing higher score in physical domain $57.7 \pm 19.1$ [11].

When we compared QOL scores between adherent and non-adherent patients, we found there was association between adherent and quality of life especially in physical domain. Epilepsy patients who being adherent with AED have better quality of life than epilepsy patients who are not adherent. Previous study in India found different results with us whereas quality of life was not significantly associated with medication adherence [3]. Others study also reported on the impact of non-adherence on QOL. Non adherent participants score significantly lower on SF-12 Mental Health and Medical Outcomes Study, on cognitive functioning surveys in addition to be more likely to report experiencing job loss and school/occupational absenteeism due to depression. On the health and work questionnaire scores, adherent participants scored higher on their own productivity, concentration, and the health and work questionnaire total. Non-adherent participants were more likely than adherent participants to report having had to miss work/school due either a seizure, thinking/memories abilities or feared embarrassment of having a seizure in front of classmates/co-workers [28]. Epilepsy is a chronic disease that relies heavily on medication in order to maximize QOL. Unlike others conditions, the effect of non-adherence can be more immediate with poor seizure control. From the findings, it's clear that improving adherence rates is not just about improving seizure control but ultimately, optimizing the QOL of people with a long term illness.

The use of cross sectional study design within all the studies inhibited determining causality, therefore prospective longitudinal designs are recommended for future research. We used MMAS8 which is a validated and reliable tool with a significant linear relationship with adherence. However, this tool has the disadvantage of recall bias, and hence, has the tendency to overestimate adherence level. In order to reduce the bias related to the assessment of adherence, questionnaire filled done by face to face to the patients and we asked the patient caregiver or family to verify the answer. For quality of life, we used WHO BREF questionnaire as a tool to measure QOL score. Because it's belong to general questionnaire, the questions may be not specific and suitable for epilepsy patients, if we compared with the questions on specific questionnaire such as QOLIE questionnaire.

\section{Conclusions and Recommendations}

Age and duration of therapy are factors that influence medication adherence in epilepsy patients on this study. Medication adherence is known to have a profound effect on the quality of life of epilepsy patients. Improving medication adherence is not just about to improve seizure control but ultimately to improve the quality of life of people with epilepsy as that is expected on epilepsy management.

\section{Acknowledgements}

This research was supported by Faculty of Medicine and Health Sciences, Universitas Warmadewa. We thank Neurology Department of Regional Hospital Denpasar for assistance during research. We also thank our colleagues from Pharmacology Department, Universitas 
Warmadewa and Universitas Gadjah Mada who provided insight and expertise that greatly assisted the research.

\section{References}

[1] M. da Mota Gomes, T. Navarno, A. Keepanasseril, R. Jeffery, R. B. Haynes. 2016. Increasing adherence to treatment in epilepsy: what do the strongest trial show? Acta Neurol Scand 1-7.

[2] A. Getnet, S. M. Woldeyohannes, L. Bekana, T. Mekonen, W. Fekadu, M. Menberu, S. Yimer, A. Assaye, A. Belete, H. Belete. 2016. Antiepileptic Drug Nonadherence and Its Predictors among People with Epilepsy. Behav. Neurol. 1-6.

[3] B. Honnekeri, S. Rane, R. Vast, S. V. Khadilkar. 2018. Between the Person and the Pill: Factors Affecting Medication Adherence in Epilepsy Patients. J. Assoc. Physic. India 06: 24-26.

[4] S. Chauhan, P. L. Prasad, B. Khurana, P. Gahalaut. 2018. Self-reported Medication Adherence to Antiepileptic Drugs and Treatment Satisfaction among Paediatric Patients Having Epilepsy: A Cross Sectional Study from Indian Subcontinent. Sri Lanka J. Child Health 47(2): 129-136.

[5] R. E. Faught, J. R. Weiner, A. Guerin, M. C. Cunnington, M. S. Duh. 2009. Impact of Non Adherence to Antiepileptic Drugs on Health Care Utilization and Costs: Finding from RANSOM Study. Epilepsia J. 50(3):501-509.

[6] O. S. Johnbull, B. Farounbi, A. O. Adeleye. O. Ogunrin, A. P. Uche. 2011. Evaluation of Factors Influencing Medication Adherence in Patients with Epilepsy in Rural Communities of Kaduna State, Nigeria. Neuroscience Biomed. J. 2(4):299-305.

[7] S. C. E. Chapman, R. Horne, A. Chater, D. Hukins, W. H. Smithson. 2014. Patients Perspectives on Antiepileptic Medication: Relationships between Beliefs about Medicines and Adherence among Patients with Epilepsy in UK Primary Care. Epilepsy Behav. 31: 312-320.

[8] P. A. Dekker. 2002. Epilepsy: A Manual for Medical and Clinical Officers in Africa. World Health Organization, Geneva, Switzerland.

[9] E. Sabat. 2003. Adherence to Long-Term Therapies: Evidence for Action, World Health Organization, Geneva, Switzerland.

[10] H. Hakonsen, E. Toverud. 2012. A Review of Patient Perspectives on Generics Substitution: What are the Challenges for Optimal Drug Use. Generics \& Biosimilars Initiative Journal 1(1): 28-32.

[11] M. Anu, K. Suresh, P. L. Basavanna. 2016. A Cross Sectional Study of Quality of Life among Subjects with Epilepsy Attending a Tertiary Care Hospital. JCDR 10(12): 1315.

[12] J. George, C. Kulkarni., G. R. K. Sarma. 2015. Antiepileptic Drugs and Quality of Life in Patients with Epilepsy: A Tertiary Care Hospital Based Study. VIHRI 6C: 1-6.

[13] P. A. N. K. Permatananda, E. Kristin, D. Endharti, R. T. Pinzon, I K. Sumada. 2018. Adverse Event of Antiepileptic Drugs: A Cross Sectional Study. MATEC Web. Conf. 19707004.

[14] R. E. Faught, J. R. Weiner, A. Guerin, M. C. Cunnington, M. S. Duh. 2009. Impact of Non Adherence to Antiepileptic Drugs on Health Care Utilization and Costs: Finding from the RANSOM Study. Epilepsia 50 (3): 501-509.

[15] C. M. M. Ferrari, R. M. C. de Sousa, L. H. M. Castro. 2013. Factors Associated with Treatment Non-adherence in Patients with Epilepsy in Brazil. Seizure 22 (5): 384-389.

[16] L. Nakhutina, J. S. Gonzales, S. A. Margolis, A. Spada, A. Grant. 2011. Adherence to Antiepileptic Drugs and Beliefs about Medication among Predominantly Ethnic Minority Patients with Epilepsy. Epilepsy \& Behavior 22 (3): 584-586.

[17] W. M. Sweileh, M. S. Ihbesheh, I. S. Jarar. 2011. Self-reported Medication Adherence and Treatment Satisfaction in Patients with Epilepsy. Epilepsy \& Behavior 21 (3): 301-305.

[18] G. O' Rourke, J. J. O' Brien. 2017. Identifying the Barriers to Antiepileptic Drug Adherence among Adults with Epilepsy. Seizure 45: 160-168.

[19] J. Eatock, G. A. Baker. 2007. Managing Patient Adherence and Quality of Life in Epilepsy. NDT 3(11): 117-131. 
[20] P. A. N. K. Permatananda, E. Kristin, D. Endharti, R. T. Pinzon, I K. Sumada. 2018. The Quality of Life of Patients with Epilepsy in Denpasar: A Cross Sectional Study. IOP Conf. Series: Materials Science and Engineering 434012327.

[21] E. Faught. 2012. Adherence to Antiepileptic Drug Therapy. Epilepsy Behav. 25: 297-302.

[22] Shi, J. Liu, V. Fonseca, P. Walker, A. Kalsekar, M. Pawaskar. 2010. Correlation between Adherence Rates Measured by MEMS and Self-Reported Questionnaires: A Meta-Analysis. Health Qual. Life Outcomes 8(99): 1-7.

[23] T. Y. Hasiso, T. A. Desse. 2016. Adherence to Treatment and Factors Affecting Adherence of Epileptic Patients at Yirgalem General Hospital, Southern Ethiopia: A Prospective Cross Sectional Study. PLoS One 11(9): 1-12.

[24] S. Banu, A. Numan. 2016. Factors Influencing Antiepileptic Drug Non Compliance in Epileptic Patients of Pakistan. Pakistan Journal of Neurological Sciences 11(1): 20-23.

[25] C. K. Mbuba, A. K. Ngugi, G. Fegan. 2012. Risk Factors Associated with the Epilepsy Treatment Gap in Kilifi, Kenya: A Cross Sectional Study. The Lancet Neurology 11(8): 688-696.

[26] E. T. Shama. 2013. Factors Contributing to Therapeutic Compliance of Epileptic Patients and the Suggestive Solutions. Journal of Biology, Agriculture, and Healthcare 3(3): 22-35.

[27] S. Gunadarma, E. Kustiowati, M. Husna. 2014. Pedoman Tata Laksana Epilepsi. Surabaya: Airlangga University Press. Pp 10-13.

[28] C. A. Hovinga, M. R. Asato, R. Manjunath, J. W. Wheles, S. J. Phelps, R. D. Sheth. 2008. Association of Non-adherence to Antiepileptic Drugs and Seizures, Quality of Life, and Productivity: Survey of Patients with Epilepsy and Physicians. Epilepsy Behav.13(2): 316-22.

\footnotetext{
*Corresponding author.

E-mail address: nayakasih@gmail.com
} 